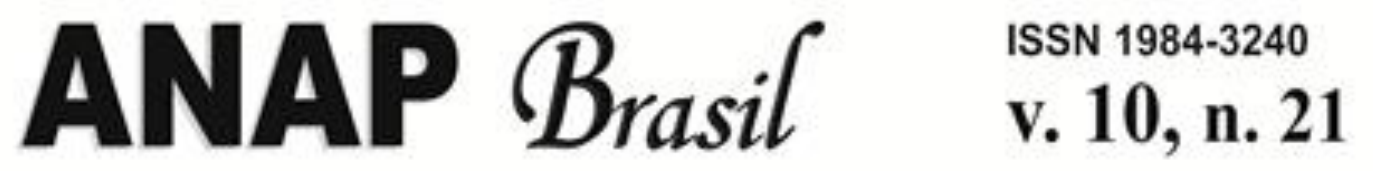

\title{
A utilização do SIG para o planejamento urbano
}

The use of GIS for urban planning

La utilización del SIG para la planificación urbana

Glauber Alexsander Batista Silva

Arquiteto e Urbanista, Brasil

Glauberalexsander@gmail.com

Priscila Lacerda Duarte David

Professora mestra, UNIP, Brasil. pridavid@gmail.com

Gislaine Bianchi Professora especialista, UNIP, Brasil. Gbianchi.arq@gmail.com 


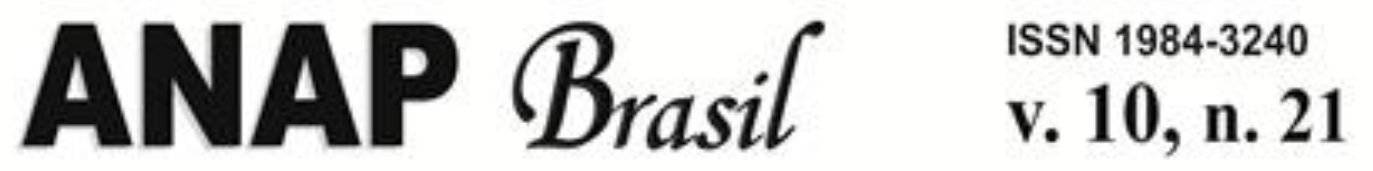

REVISTA CIENTIFICA 2017

\section{RESUMO}

O planejamento urbano tem buscado melhorarias para a qualidade de vida dos habitantes e estruturas para o espaço urbano. Nesse sentido, o objetivo desde artigo é mostrar como o SIG - Sistema de Informação Geográfica pode auxiliar no planejamento urbano. A ferramenta é um conjunto de programas para processamento e análise de dados georreferenciados. O SIG mostra uma visão ampla sobre a cidade e pode possibilitar o fornecimento de serviços de qualidade para a população, distribuídos geograficamente de maneira uniforme pelo município. Esse trabalho traça um panorama da utilização do SIG para o planejamento urbano, sobretudo em cidades brasileiras e estuda os impactos que a implantação do SIG teria em uma cidade de médio porte no interior do estado de São Paulo, Birigui.

PALAVRAS-CHAVE: Geotecnologia, SIG, Gestão Municipal, Planejamento Urbano.

\section{ABSTRACT}

Urban planning has sought improvements for the quality of life of inhabitants and structures for urban space. In this sense, the purpose of the article is to show how the GIS - Geographic Information System can assist in urban planning. The tool is a set of programs for processing and analyzing georeferenced data. The GIS shows a broad view of the city and can enable the provision of quality services for the population, geographically distributed in a uniform way by the municipality. This work outlines the use of GIS for urban planning, especially in Brazilian cities, and studies the impacts that GIS implantation would have on a medium-sized city in the interior of the state of São Paulo, Birigui.

KEY WORDS: Geotechnology, GIS, Municipal Management, Urban Planning.

\section{RESUMEN}

La planificación urbana ha buscado mejoras para la calidad de vida de los habitantes y las estructuras para el espacio urbano. En ese sentido, el objetivo desde el artículo es mostrar cómo el SIG - Sistema de Información Geográfica puede auxiliar en la planificación urbana. La herramienta es un conjunto de programas para el procesamiento y análisis de datos georreferenciados. EI SIG muestra una visión amplia sobre la ciudad y puede posibilitar el suministro de servicios de calidad para la población, distribuidos geográficamente de manera uniforme por el municipio. Este trabajo traza un panorama de la utilización del SIG para la planificación urbana, sobre todo en ciudades brasileñas y estudia los impactos que la implantación del SIG tendría en una ciudad de mediano porte en el interior del estado de São Paulo, Birigui.

PALABRAS CLAVE: Geotecnología, SIG, Gestión Municipal, Planificación Urbana. 


\section{ANAP $B_{\text {rasil }}$

\section{Introdução}

Para Villaça (1999) Planejamento Urbano é uma organização dos espaços urbanos de forma especifica. O planejamento urbano busca melhorar a qualidade de vida dos habitantes, além de desenvolver estruturas para o espaço urbano organizado. (HOFFMANN, et al, 2011) O planejamento urbano contemporâneo, tem seu foco na recuperação e ocupação dos espaços obsoleto para atividades industriais e no desenvolvimento econômico municipal, além de valorizar cada vez mais a qualidade de vida. Algumas renovações e intervenções usam o mesmo solo e até o mesmo desenho espacial existente. (CAVALCANTI, 2008)

O sistema de informação geográfica - SIG é uma das melhores ferramentas para tomadas de decisões sobre planejamentos urbano, e suas aplicações pode ser muito eficaz através de mapas e bancos de dados que abrangem as características do local. (TEIXEIRA, 1995)

O SIG é um "conjunto de programas, equipamentos, metodologia, dados e pessoas (usuários), perfeitamente integrados, de forma a tornar possível a coleta, o armazenamento, o processamento e a análise de dados georreferenciados, bem como a produção de informação derivada de sua aplicação" (TEIXEIRA, 1995, p. 20).

O objetivo desta pesquisa é mostrar a aplicação do SIG para auxiliar no planejamento urbano, no que diz respeito ao acesso de dados geográficos, para ajudar o urbanista no diagnostico, projeto e apresentação dos resultados de seu trabalho.

\section{O SIG nas questões urbanas}

Espera-se de qualquer prefeitura serviços de qualidade como: estradas pavimentadas, escolas, transporte público coletivo, coleta de lixo, distribuição e tratamento de água. Esses serviços são distribuídos geograficamente pela cidade, e ter ciência destas informações é essencial para o seu funcionamento.

Sendo assim, o sistema de informações geográficas, tem sido muito útil para a administração pública, possibilitando uma visão mais ampla sobre a cidade e ajudando na tomada de decisões.

A utilização do SIG junto com as imagens de satélites, além de trazer contribuições para o desenvolvimento do Plano Diretor, como ajudar várias secretarias do município a planejar e disponibilizar suas ações e informações. (CAVENAGHI, LIMA, 2006).

Assim, facilitando e melhorando a vida dos habitantes, disponibilizando informações como, por exemplo: saúde, educação, habitação, IPTU, transportes e pontos turísticos. Além disso, o SIG agiliza o direcionamento das decisões das prefeituras tendo como exemplo: a área tributária, o planejamento urbano, a saúde, a educação e a construção do Plano Diretor.

O SIG pode ser utilizado de formas diferentes de acordo com as necessidades de cada secretaria. A imagem 1 abaixo mostra como o SIG atente as diferentes necessidades de diferentes secretarias

Imagem 1: Uso de SIG na administração municipal 


\section{ANAP Brasil \\ ISSN $1984-3240$ \\ v. 10, n. 21}

\section{REVISTA CIENTIFICA 2017}

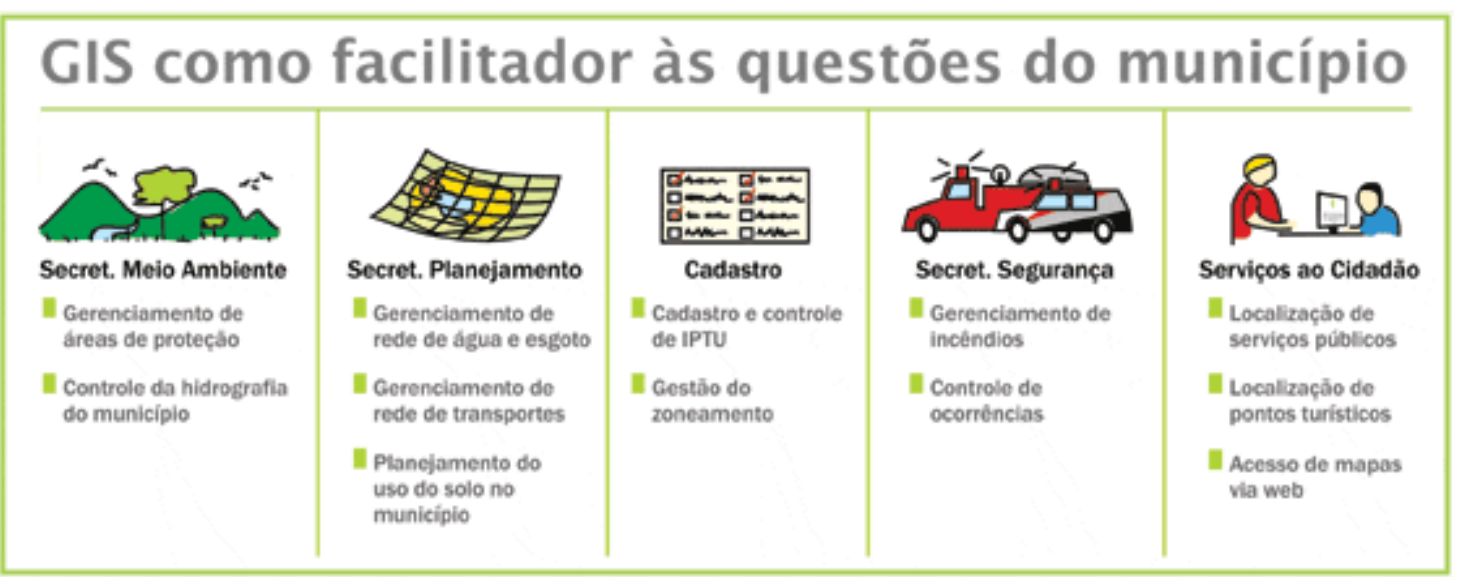

Fonte: Cavenaghi e Lima, 2006

Vieira (2006) explica que aplicações WEB integradas a um ambiente de geotecnologia, já são muito comuns em países que adotaram esse recurso, e assim passou a ser um aliado dos administradores, governantes e dos cidadãos. Vieira ainda completa "O uso da internet para criar um sistema de planejamento participativo e gestão pública mais ágil foi batizado de "egovernment", ou "governo eletrônico".

Governantes utilizam muito a web para recolhimento de imposto e taxas via web, porém quando se agrega a vertente "geo", esse instrumento de administração se potencializa e ultrapassa a barreira do limite para a facilitação do processo administrativo.

Alguns exemplos que mostra a utilização do SIG no e-goverment são:

- Aplicações em desenvolvimento econômico: Para promover o desenvolvimento econômico municipal, o SIG na web pode facilitar no processo de licenciamentos e aprovações de projetos urbanos, ambientais e de construções, aceitando pareceres ao zoneamento urbano e ao uso de solo municipal, tornando mais prático para investidores tomar decisões observando um mapa na WEB, e planejando seus passos de forma prática e acelerada. (DORETTO, MONTANHA, 2006).

- Aplicações em cidadania - participação popular: A internet é sem dúvida a forma mais rápida de propagar e de obter alguma informação, de tal modo a sua inserção na comunidade tem sido amplamente agregada. A população por meio do SIG na WEB, tem acesso mais rápido a horários e trajetos de linhas de transporte público; localização dos serviços de saúde e educação mais próximos, bem como os serviços por eles prestados. (DORETTO, MONTANHA, 2006).

- Aplicações governo-governo: O SIG integrado com a internet consegue com que secretarias e órgãos públicos se conectem, deixando de ter redundâncias e duplicidade de dados, facilitando que as diferentes esferas politicas trabalhem de forma conjuntas, tanto em abrangência municipal, quanto regional e até mesmo estatual, agilizando vários tipos de ações, especialmente as emergenciais. (DORETTO, MONTANHA, 2006).

O SIG também pode ajudar a prefeitura em um senso social, obtendo um banco de dados com uma vasta informação de famílias residentes no município. Com informações é possível 


\section{ANAP Brasil \\ ISSN 1984-3240 \\ v. 10, n. 21}

REVISTA CIENTIFICA 2017

direcionar futuras políticas de investimentos, desenvolvimento e ações sociais. (DORETTO, MONTANHA, 2006).

Esse banco de dados é feito a partir de entrevistas em cada residência da cidade. A forma de moradia, necessidades especiais, grau de escolaridade, renda média familiar, quantidade de desempregados, etc, são algumas das questões que pode ser abortada pelo entrevistador. (DORETTO, MONTANHA, 2006).

Todavia, há dificuldades de se implantar essa tecnologia em países em desenvolvimento, entre os principais motivos estão: falta de qualificação profissional, desconhecimento de tais tecnologia, além das dificuldades financeiras. Porém, Duarte (2010) levantou que "em países desenvolvidos e também em países da América Latina revelam alto índice de benefício sobre custo, refletindo diretamente na qualidade de vida dos munícipes e no aumento da arrecadação municipal".

\section{A atuação do SIG no planejamento urbano}

A implantação do SIG nas cidades dos Estados Unidos, são um pouco diferentes da realidade brasileira, pois há um banco de dados já prontos, sendo assim o ponto de partida para implantar o SIG é a escolha do conteúdo de bases de dados. Em geral, o cadastro e a valorização da propriedade já são automatizados. (SCHUCH, 2001)

Com esta abundancia de informações, o SIG é muito utilizado para assistência a serviços de emergência, a cidade de Dentre no Colorado por exemplo, implementou o SIG onde indica a posição do Ônibus, Schuch explica que "durante as tormentas de neve, os ônibus frequentemente se perdiam."

Na cidade de Indianapolis em Indiana, usa a localização de bombeiros, policiais e ambulância, diante disso os operadores conseguem identificar as coordenadas da ligação e indicar o veículo de emergência mais próximo para ir ao local. ( $\mathrm{SCHUCH,} \mathrm{2001)}$

Porém em muitas cidades americanas não há a implantação do SIG por razões semelhantes as encontradas nas cidades brasileiras, pois o que se tem de prioritário para a cidade é a instalação de uma rede de esgoto, e não a implantação do SIG. (SCHUCH, 2001)

Em Tupã, uma cidade localizada no estado de São Paulo, a $530 \mathrm{~km}$ de distância da capital, a Prefeitura adotou a implantação do SIG, para resolver alguns problemas habituais que continuam aos longos de anos.

Doretto e Montanha (2006) explica que "O conhecimento das bases sociais do município definhou de um lado e de outro, e perdeu-se o controle do estoque da dívida ativa, dos gastos e das bases cadastrais, que se perderam no tempo" e assim houve um descontrole fiscal. Com isso a prefeitura deixa de ter capacidade para investimentos, deixando de aumentar o desenvolvimento econômico e social.

O programa começa usando o SIG e uma base cartográfica. Atualmente há várias tecnologias que pode nos oferecer essa base cartográfica, como os VANT's, aviões e satélites, sendo que cada um tem seus prós e contras para cada situação. Com essas informações inicia-se a vetorização e o cadastramento dos dados para a composição de uma base cartográfica digital do município atualizada. Com a pose deste banco de dados junto com bases cadastrais da 


\section{ANAP Brasil \\ ISSN 1984-3240 \\ v. 10, n. 21}

\section{REVISTA CIENTIFICA 2017}

Prefeitura é possível então indicar por exemplo imóveis que possuem alguma irregularidade como a diferença da área total construída declarada pelo contribuinte junto com o poder público. (DORETTO, MONTANHA, 2006).

Uma das utilizações feita pela prefeitura de Tupã, foi analisar se os imóveis estão com a metragem quadrada de acordo com os registros do IPTU, e para isso foi feito um levantamento fotogramétrico da cidade, como mostra a Imagem 2, depois de todos os dados processados, é feita uma vetorização dos lotes e das casas assim como na imagem 3 e 4 onde o programa indica todas as informações do lote como na imagem 5

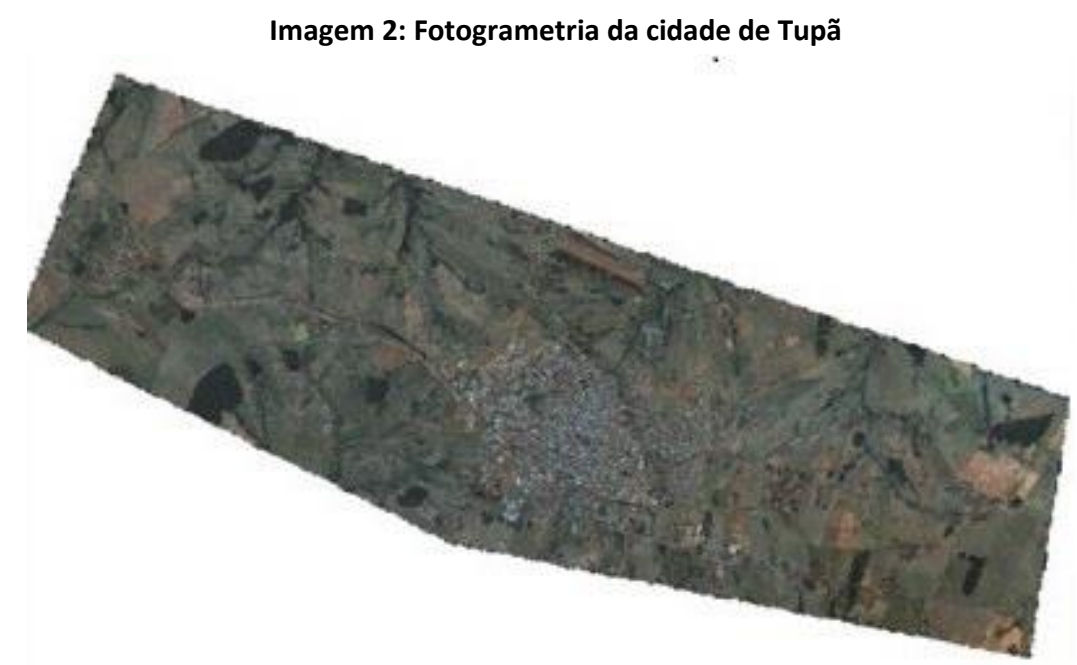

Fonte: Doretto e Montanha, 2006 


\section{ANAP Brasil \\ ISSN 1984-3240 \\ v. 10, n. 21}

REVISTA CIENTIFICA

2017

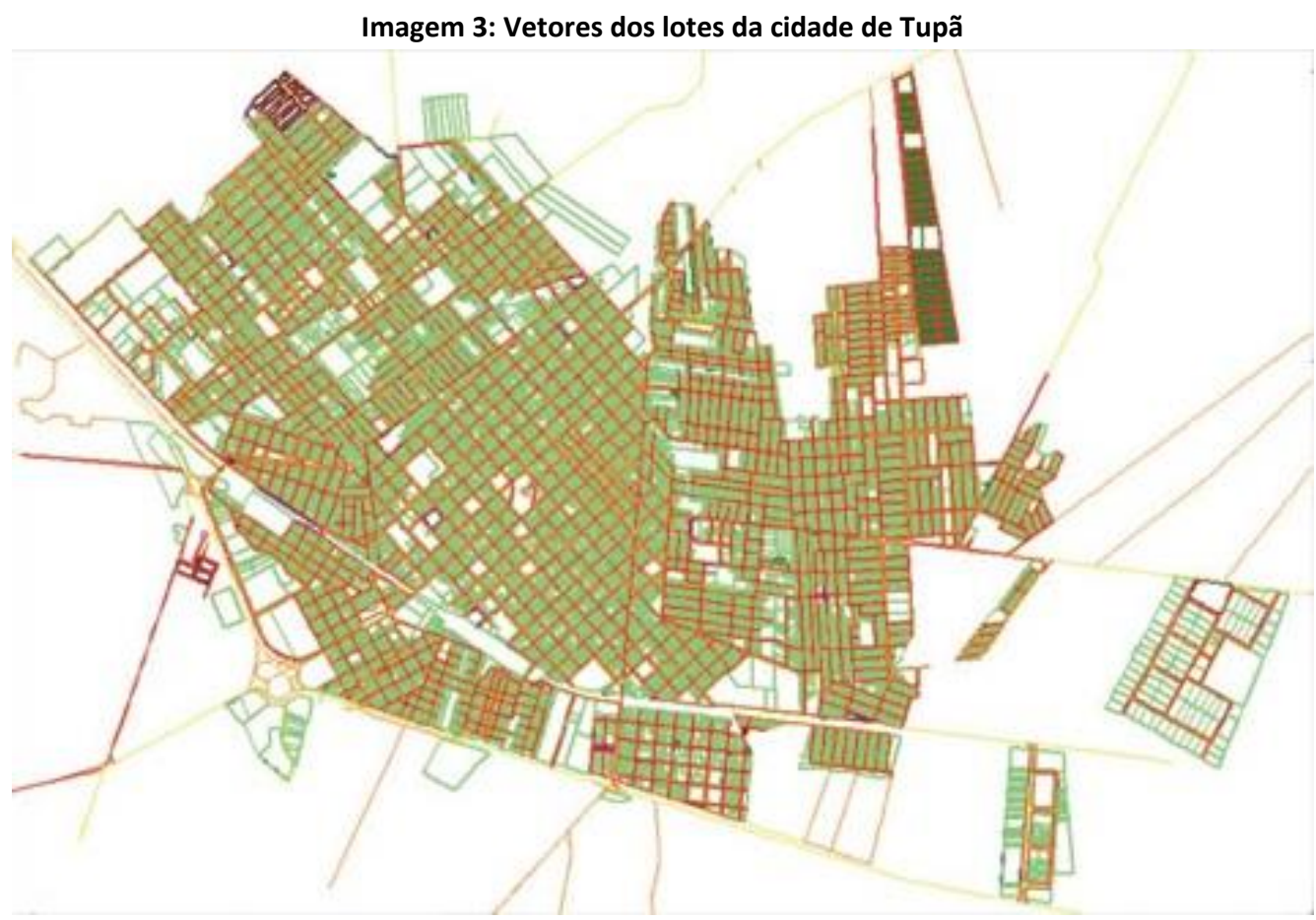

Fonte: Doretto e Montanha, 2006

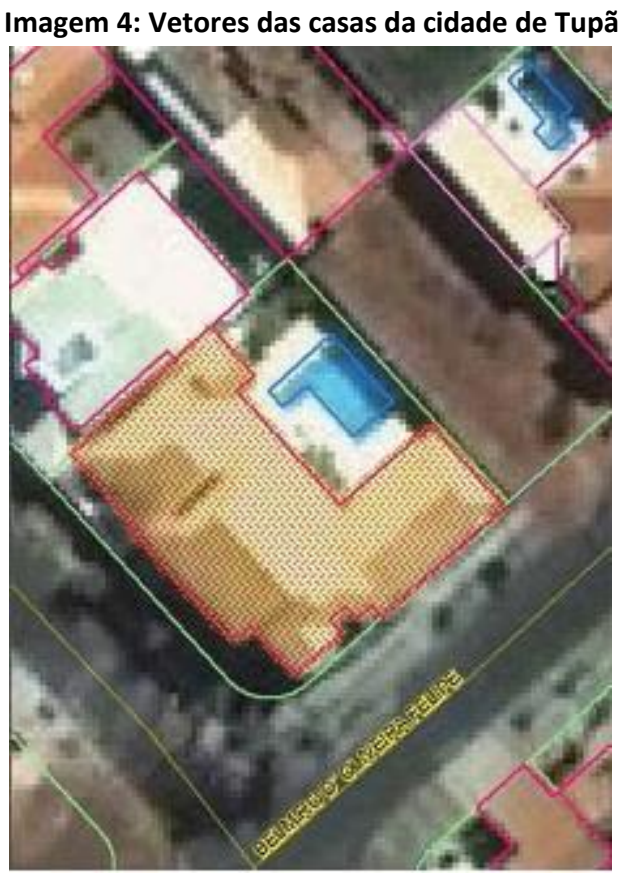

Fonte: Doretto e Montanha, 2006 


\section{ANAP $B_{\text {rasil }}$

\section{REVISTA CIENTIFICA 2017}

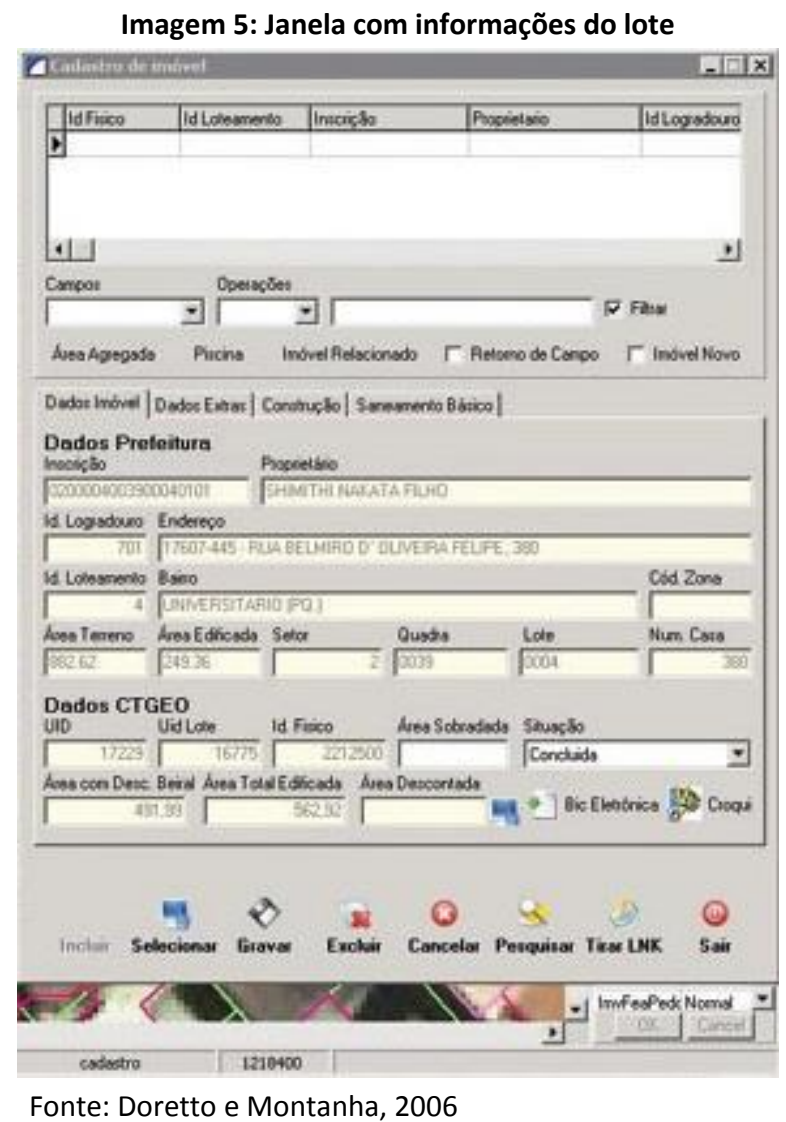

O prefeito de Tupã a época, Waldemir Gonçalves Lopes, explicou que com o uso desta tecnologia, possibilitou um controle das despesas correntes e aumento de $60 \%$ nos investimentos com recursos, assim a prefeitura teve uma maior independência. "A prefeitura passou a trabalhar para a cidade e não o contrário", com isso o município pode investir mais e melhor para a população. (DORETTO, MONTANHA, 2006).

A Arquiteta Ana Clara Mourão Moura, (2004) em sua tese de mestrado em geografia para a UFRJ, determinou um sistema de geoprocessamento para planejamento urbano e promoção de ferramentas de gestão e apoio à decisão na proteção do Patrimônio Histórico de Ouro Preto, situada próxima a Belo Horizonte, no estado de Minas Gerais.

Com base na metodologia da autora, foi criado um Sistema Informativo Geográfico de base matriarcal, sendo possível organizar um banco de dados de diferentes fontes, e construindo analises de diferentes naturezas, em fórmulas para diagnósticos e prognósticos.

Com toda essa informação compilada, foi preparado um Sistema de Gerenciamento Eletrônico de Documentação, juntando as variáveis georreferenciada e navegação virtual para estudo de impacto paisagístico. O objetivo deste sistema é acompanhar o procedimento de intervenção na paisagem urbana. (MOURA, DA SILVA, 2004). 


\section{ANAP $B_{\text {rasil }}$

\section{REVISTA CIENTIFICA 2017}

\section{Analise de Implantação na Cidade de Birigui - SP}

Birigui é uma cidade situada na região Noroeste Paulista, no estado de São Paulo (Imagem 6). Assim como algumas cidades na região, tem sua origem pelo aumento da economia cafeicultora, sendo que sua ocupação urbana começou a partir da Estrada de Ferro Noroeste Paulista em 1908. E, só em 1913 começou o procedimento de arruamento do povoado e estruturas básicas, chegando a ter em média duzentas famílias habitando a vila, Birigui se tornou o Distrito de Paz de Penápolis, e em 1921 passou a ser uma cidade. (MIYAZAKI, 2013).

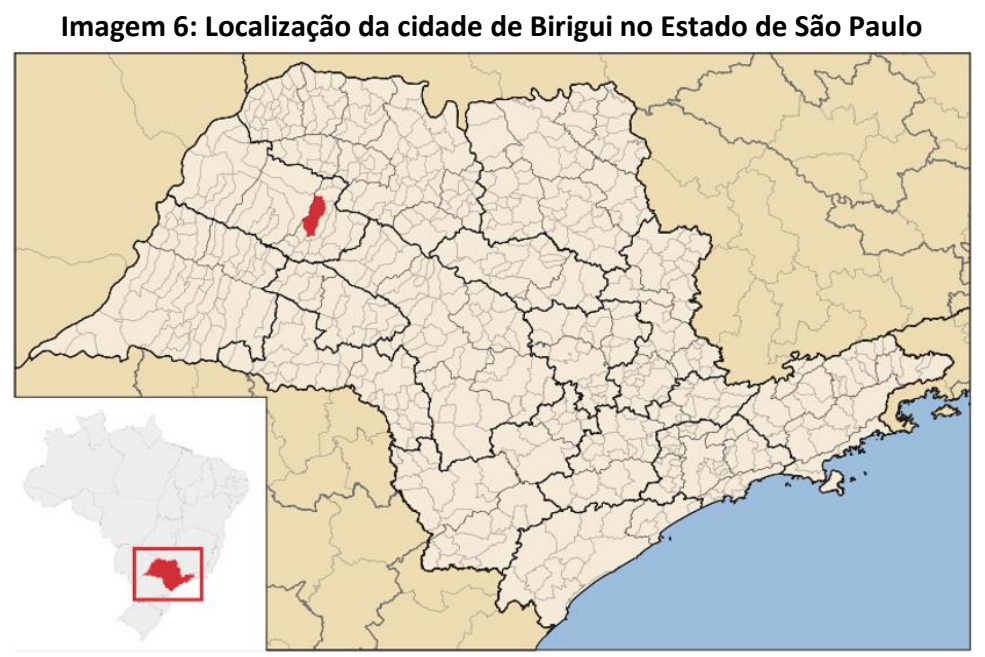

Fonte: http://migre.me/wEj8y. Acesso em 19 de mai. de 2017

O município segue as diretrizes do Plano Diretor, aprovado em 2006. E atualmente a cidade tenta resolver os problemas conforme aparecem, sem se precaver para o futuro.

Com o SIG, Birigui teria a possibilidade da realização um senso social na cidade para determinar precisamente o local que tem mais famílias carentes, regiões com carência de edifícios públicos, como por exemplo, creches, escolas, UBS, centros de lazer, também pode ser decidido onde há a necessidade de manutenções hidro sanitárias, em redes de energia elétrica e em pavimentações.

O SIG em conjunto com o levantamento fotogramétrico, irá auxiliar na arrecadação, onde irá obter um levantamento mostrando se há divergência entre as informações dos imóveis e com as que constam no cadastro municipal, assim arrecadando mais imposto para o município.

Outra questão é o monitoramento em tempo real do transporte público, onde o usuário poderá acompanhar pela internet onde o veículo está e ir para o ponto de parada mais próximo.

Além disso a Secretaria de Segurança Pública, irá visualizar onde estão cada viatura e quem está utilizando a viatura no momento, enviar a que se encontra mais próxima do local da ocorrência de algum problema, estendendo sua praticidade aos bombeiros e viaturas municipais.

O SIG pode auxiliar Birigui no mapeamento, gerenciamento e monitoramento do seu meio ambiente e áreas de preservação permanentes, pois o SIG permite o armazenamento, 


\section{ANAP Brasil

atualização dos dados, que com o crescimento populacional está cada vez mais escasso atualmente.

\section{Conclusão}

O desenvolvimento deste estudo possibilitou uma análise de como um Sistema de Informação Geográfica pode ser um benefício para os municípios, auxiliando-os nas tomadas de decisão, e trazendo facilidades para a população. Essa tecnologia tem tudo para facilitar a gestão municipal. Sua utilização pode ser adaptada a qualquer tipo de cidade, os exemplos citados são um modelo de que o SIG beneficia e melhora o município. Atualmente está cada vez mais difícil ser um gestor municipal, e a tecnologia é um meio de facilitar a troca de informações tanto para a gestão quanto para os moradores, principalmente com a internet, que é uma ferramenta instantânea e que pode ser confiável.

\section{Referências}

CAVALCANTI, Rafaela Campos. O Projeto Urbano Contemporâneo Competição Global e Coesão Socioespacial. UFPE. Recife-PE. 2008

CAVENAGHI, T. P.; LIMA, M. Plano Diretor: Como a Geotecnologia tem Facilitado a Gestão dos Municípios. Mundo Geo, Curitiba. PR, nov 2006. Disponível em: < http://mundogeo.com/blog/2000/01/01/plano-diretor-como-a-geotecnologia-tem-facilitado-a-gestaodos-municipios> Acesso em: 21 abril. 2017.

DORETTO, E. S.; MONTANHA, P. N. Geoprocessamento para Controle das Políticas Públicas. Mundo Geo, Curitiba. PR, nov 2006.

DUARTE, Romero Meyrelles. Geoprocessamento no Planejamento Urbano. Mundo Geo, dez 2010. Disponivel em: < http://mundogeo.com/blog/2010/12/15/geoprocessamento-no-planejamentourbano/> Acesso em: 22 de abril. 2017

HOFFMANN, Rosa Cristina. MIGUEL, Renato Abib Dutra. PEDROSO, Daiane Cristina. A importância do planejamento urbano e da gestão ambiental para o crescimento ordenado das cidades. Revista de Engenharia e Tecnologia, V. 3, No. 3, Dezembro, 2011

MIYAZAKI, Vitor Koiti. Estruturação da cidade e morfologia urbana: um estudo sobre cidades de porte médio da rede urbana paulista. UNESP. Presidente Prudente-SP, 2013

MOURA, A. C. M.; DA SILVA, J. X. Geoprocessamento Aplicado à Caracterização e Planejamento Urbano de Ouro Preto - MG. In: DA SILVA, J. X.; ZAIDAN, R. Geoprocessamento e Análise Ambiental Aplicações. Rio de Janeiro-RJ: Bertrand Brasil, 2004

SCHUCH, Harold C. GIS e Prefeituras. REVISTA INFOGEO ONLINE, dez 2001. Disponivel em: < http://mundogeo.com/blog/2001/12/01/gis-e-prefeituras/> Acesso em: 03 de Maio. 2017

TEIXEIRA, A. et al. Qual a melhor definição de SIG. Revista FATOR GIS, n.11, 1995.

VIEIRA, I. M. Planejamento Municipal e Planos Diretores: A Geotecnologia como Aliada. Mundo Geo, Curitiba, PR, nov 2006 


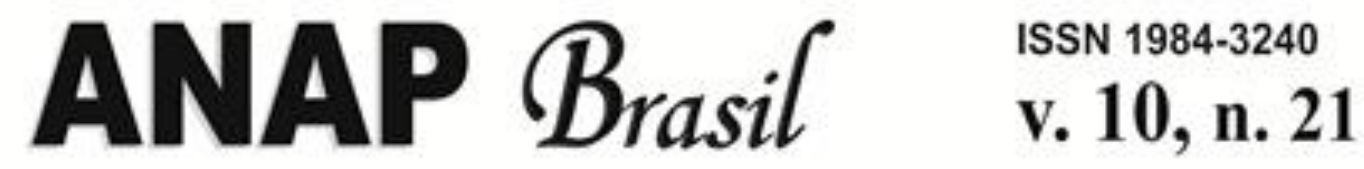

REVISTA CIENTIFICA 2017

VILLAÇA, F. Uma contribuição para a história do planejamento urbano no Brasil. In $O$ Processo de Urbanização no Brasil: falas e façanhas. São Paulo: Editora Universidade de São Paulo, p.171, 1999. 